\title{
Vài suy nghĩ tự sự lịch sử và văn chương nhân một tình tiết nghiên cứu Tam quốc chí diễn nghĩa của Hsia Chih-Tsing
}

\section{Some thoughts of narrations in history and literature in response to CT.Hsia's research detail in The Romance of the Three Kingdoms}

\author{
Lê Thời Tân ${ }^{1 *}$ \\ ${ }^{1}$ Trường Đại học Giáo Dục, Đại học Quốc gia Hà Nội, Việt Nam \\ *Tác giả liên hệ, Email: tanlt@vnu.edu.vn
}

THÔNG TIN

DOI: $10.46223 / \mathrm{HCMCOUJS.}$ soci.vi.13.1.884.2017

Ngày nhận: 22/04/2016

Ngày nhận lại: 02/06/2016

Duyệt đăng: 12/01/2017

Tù khóa:

Hạ Chí Thanh, Tam Quốc, diễn nghĩa, tự sự tiểu thuyết, sử kí

Keywords:

C.T.Hsia, Three Kingdoms, fictional narrations, history records, "Bronze Sparrow Mansion"

\section{TÓM TẮT}

Trao đổi của chúng tôi với C.T.Hsia xoay quanh chú dẫn liên quan đến tình tiết "Đồng Tước Đài Phú" trong Tam Quốc Chí Diễn Nghĩa. Chú dẫn này cho thấy nhà nghiên cứu vô hình trung không có phân biệt người và việc trong sư với người và việc trong văn. Tâm lí nệ sử và phản xạ khảo cứu vị khảo cứu vô hình trung đã trở thành chướng ngại vật trên con đường đọc hiểu tự sự tiểu thuyết. Mải vận dụng kiến thức sử kí để chú dẫn một cách cô lẻ tình tiết tự sự trong tiểu thuyết khiến nhà nghiên cứu quên đi bản thân mình thực ra đang "vãng cảnh" ngôi đài được "dựng lên" trong văn chương chứ không chỉ là một di tích bên bờ con sông lịch sử ! "Đài chim sẻ đồng” bên bờ sông Chương đó đã lưu danh "Đồng Tước" vào trong Tam Quốc Chí và Tam Quốc Chí Diễn Nghĩa theo những cách khác nhau. Tiểu thuyết và sử kí đã khác nhau thì Diễn Nghĩa của nhà phê bình văn chương và nhà nghiên cứu lịch sử cũng đâu có thể cùng một cách thức! Bài viết này chính là xoay quanh một tinh thần cơ bản như thế.

\begin{abstract}
Our responses to C.T.Hsia's research focus on his research detail of Bronze Sparrow Mansion Ode (The Romance of the Three Kingdoms). This detail shows that he unconsciously did not separate fictional characters/incidents and historical heroes/events. The habit of history worshipping and the trend to do documenting for documenting have unconsciously formed a barrier to understanding fictional narrations. While making use of his knowledge of history to interpret a single narrative incident in fiction, the researcher forgot that he was actually looking at the mansion 'erected' in literature, not a historical building.
\end{abstract}


'Bronze Sparrow Mansion' by Zhang River made its name known in Records of the Three Kingdoms (Sanguozhi) and The Romance of the Three Kingdoms (Sanguozhi Yanyi) in different ways. As long as novels and history records are different, the review made by literature critics and that by history researchers cannot be the same. This responding article revolves around the above concept.

Trung Quốc Cổ điển Tiểu thuyết Sử luận (Hsia Chih-tsing, The Classic Chinese Novel: A Critical Introduction) của học giả người Hoa quốc tịch Mĩ Hạ Chí Thanh là một trong số những tác phẩm viết bằng tiếng Anh xuất bản tại phương Tây giới thiệu tập trung năm bộ tiểu thuyết Minh Thanh nổi tiếng nhất. ${ }^{1}$ Hướng tới độc giả phương Tây nên tác giả sách này chú ý dẫn dịch nhiều trường đoạn trong các bộ tiểu thuyết cổ điển Trung Quốc. Chẳng hạn đến chương viết về Tam Quốc Chí Diễn Nghĩa, Hạ Chí Thanh đã chọn dẫn trọn vẹn cả trường đoạn kể chuyện Tào Tháo mở tiệc giữa đêm rằm trên Trường Giang trước đại chiến Xích Bích. ${ }^{2}$ Sau đoạn dẫn, Hạ Chí Thanh viết (chúng tôi dẫn kèm cả chú thích của chính tác giả - phần chú thích được đặt vào trong ngoặc đơn và in nghiêng để phân biệt - LTT):

"Đối với La Quán Trung, đây có lẽ là một trong những màn "tiểu thuyết hóa" nhất trong tác phẩm. Chính sử không thấy kí tải về bữa đại tiệc này. Thế nhưng việc xây dựng màn tiệc này hoàn toàn hợp với tính cách Tào Tháo - trước trận đại chiến mà thắng lợi đã được dự trù, nhất định cần sửa soạn một buổi thịnh yến. Vào thời đó, cho dù là ở Trung Quốc hay quốc gia nào, một người tuổi đã 55 không còn được coi là còn tráng niên nữa, thế mà Tào Tháo vẫn còn trên yên ngựa rong ruổi binh nhung. Vì thế, những lời Tháo nói trong bữa tiệc tỏ rõ tư thế tự đánh giá phong độ anh hùng cái thế, niềm tự đắc tin vào chiến thắng trong tầm tay. Đồng thời Tào Tháo cũng thoáng thấy chút mệt mỏi, những mong sau khi dẹp xong Đông Ngô, hai hoa khôi nước Ngô Đại Kiều và Tiểu Kiều sẽ cùng vui tuổi già bên ông ta (bài Phú Đài Đồng Tước của con trai Tào Tháo - thi nhân Tào Thực quả có nhắc đến hai mĩ nhân này). Tiểu thuyết trước đó mấy hồi cũng đã kể chuyện Gia Cát Lượng vờ không biết nhị Kiều đã gả cho ai, cố tình dẫn bài này ngay trước mặt Chu Du để kích tướng Ngô quyết tâm kháng Tào" (Xem hồi 44. Gia Cát Lương có lẽ đã mắc phải một nhầm lẫn nho nhỏ về mặt thời gian khi dẫn bài phú. Bài phú này không thể viết xong truớc ngày Đồng Tước Đài được xây xong. Đồng Tước Đài xây xong năm Kiến An thứ 15 - chú thích của chính tác giả). Tác giả tiểu thuyết trong trường hợp trên đã vận dụng rất thành công các thi phẩm nổi tiếng" (Hsia, 2001).

\footnotetext{
${ }^{1}$ The Classic Chinese Novel: A Critical Introduction của Hsia Chih-tsing có bản dịch tiếng Trung 中国古典小说 史论. Chúng tôi dẫn lại Hạ Chí Thanh từ bản dịch tiếng Trung này

${ }^{2}$ Hồi 48 宴長江曹操賦詩 鎖戰船北軍用Yến Truờng Giang Tào Tháo phú thi, Tỏa chiến thuyền Bắc quân dụng vo
} 
Điều đầu tiên phải nói là, chúng tôi không rõ nhà nghiên cứu dựa được vào tài liệu nào để khẳng định bài Phú Đài Đồng Tước 銅雀臺賦 của “con trai Tào Tháo - thi nhân Tào Thực" quả có nhắc đến hai nàng Kiều ${ }^{3}$ Thực ra ngược lại, chính bởi vì Đồng Tước Đài Phú không có nhắc đến hai mĩ nhân họ Kiều nên màn tự sự “Khổng Minh dụng trí kích Chu Du” (孔明用智 激周瑜hồi 44) mới trở nên khả thủ và thú vị được đến dường đó. Thế nhưng điều quan trọng ở đây không phải là ở chỗ có thể còn có thêm hay không một dị bản Đồng Tước Đài Phú nào đó (chứng minh là nguyên tác của Tào Thực) có nhắc chị em cô Kiều. Vấn đề là cái tâm thức nệ khảo cứu bộc lộ ra trong cách nói của nhà nghiên cứu. Hạ Chí Thanh vô hình trung không có phân biệt nhân vật lịch sử và nhân vật tiểu thuyết. Vấn đề đối với ông tỏ ra khá đơn giản: Tào Tháo thấm mệt, chỉ muốn dẹp xong Đông Ngô bắt hai Kiều về vui thú tuổi già (đây là lịch sử?) và chuyện này có thể tìm chứng cứ ở bài phú Đồng Tước Đài (một việc có thể khảo cứu). Tâm thức trọng khảo cứu và nệ sử đó bộc lộ còn rõ ràng hơn trong những dòng chú thích liên quan đến việc Khổng Minh đọc bài phú trước mặt $\mathrm{Chu} \mathrm{Du}$ - "Gia Cát Luợng có lẽ đã mắc phải một nhầm lẫn nho nhỏ về mặt thời gian khi dẫn bài phú”. Cứ như thiển ý của chúng tôi, Gia Cát Lượng của Tam Quốc Chí Diễn Nghĩa chẳng việc gì phải bận tâm đến chuyện đó. Là một nhân vật (tiểu thuyết), "hắn" ta không quản đến cái gọi là "nhầm lẫn về mặt thời gian" (!). Không nhẽ ta lại đi trách Khổng Minh không thật thà hoặc nhầm lẫn khi nói với Chu Du rằng “Luợng tôi thuở còn ở Long Trung đã nghe nói Tào Tháo cho xây một cái đài bên sông Chuơng Đài, gọi là Đồng Tước Đài...” (hồi 44). Mặt khác, không cứ đài Đồng Tước xây xong Tào Thực mới làm bài phú này. Vẫn lời Khổng Minh ("mách” với Chu Du !): “Con nhỏ của Tào Tháo là Tào Thưc, tự Tư Kiến, có tài đặt bút thành văn. Tháo bảo làm bài phú goi là "Đồng Tước Đài phü". Ý trong bài phú nói Tào gia đáng làm thiên tử và thề lấy hai Kiều" (hồi 44; trong Tam Quốc Chí Diễn Nghĩa không thấy nói chuyện Đồng Tước Đài xây xong Tào Thực mới viết bài phú). ${ }^{4}$ Thực ra, sẽ rất đáng chú ý khi nghiên cứu văn học sử (tác giả và tác phẩm) mà nêu được vấn đề cụ thể kiểu "Bài phú này không thể viết xong trước ngày Đồng Tước đài được xây xong". Thế nhưng ở đây nhà nghiên cứu rõ ràng là đang tiếp xúc với người và việc trong tiểu thuyết. Ta không thể nói về người-vật-việc trong tiểu thuyết như là nói về cũng người-việc-vật đó trong đời thực. Gia Cát Lượng trong Tam Quốc Chí Diến Nghĩa chả chịu trách nhiệm gì về việc "nhầm” thời gian sáng tác bài phú của Tào Thực và Tào Thực này cũng chẳng buộc nhất định phải viết bài phú trước hay sau sự kiện hoàn công Đồng Tước Đài! Thậm chí nói cho cùng ta cũng chả chất vấn nghiêm trang được như thế về chuyện đó với tác giả cuốn sách La Quán Trung! Tương tự, ta cũng không thể "nhắc nhở” Đỗ Mục khi viết "Đông phong bất dữ Chu Lang tiện, Đồng Tước Xuân thâm tỏa nhị Kiều” thì phải nhớ vào lúc Ngô Ngụy dàn trận Xích

\footnotetext{
${ }^{3}$ Thực ra đâu là "nguyên tác” của Tào Thực? Bản chú dẫn trong Tam Quốc Chí (Trần Thọ, Bùi Tùng Chi) hay bản “dẫn” ở Tam Quốc Chí Diễn Nghĩa (Mao bản)? Cứ như thống kê của Tư Khố Toàn Thu Đề Yếu (欽定四庫全書 總目提要) thì phú Tào Thực có 44 bài tập trung ở bốn quyển đầu trong Tào Tủ Kiến Tập (曹子建集). Tác phẩm gọi là "Đồng Tước Đài Phú” nói ở đây chính là bài “Đăng Đài Phư" (登台赋) trong tổng tập này (Tao Thuc, 1998)

${ }^{4}$ Tử Vi Lang (La Quán Trung, Tam Quốc Chí Diễn Nghĩa, lời bình Mao Tôn Cương, dịch thuật Tử Vi Lang, Nxb.Văn hoá Thông tin, 2006) dịch "Khi xây xong đài Đồng Tước, Tháo sai con làm bài phú..." - không biết dịch giả dựa cụ thể bản nào? Nhân tiện cũng xin chú ý: Trong Tam Quốc Chí, Khổng Minh du thuyết Tôn Quyền đánh Tào chứ không phải là mưu khích Chu Du. Truyện về Khổng Minh trong bộ sử này hoàn toàn không có trần thuật về Đồng Tước Đài và chuyện Nhị Kiều
} 
Bích thì Đài Đồng Tước chưa xây. Tâm lí nệ sử và phản xạ khảo cứu vị khảo cứu vô hình trung đã trở thành chướng ngại vật trên con đường đọc hiểu tự sự tiểu thuyết Tam Quốc. Như chúng tôi từng có dịp chỉ rõ tâm lí nệ sử đó cũng bộc lộ hết sức rõ ràng ở chú thích "Nhị Kiều" trong bản in Tam Quốc Diễn Nghĩa của Nhân dân Văn học Xuất bản xã (Le, 2013). ${ }^{5}$

Thực ra, chúng ta không rõ trong chú thích trên của Hạ Chí Thanh, Gia Cát Lượng được hiểu là nhân vật trong tiểu thuyết hay là người trong sư? Nếu hiểu theo nghĩa thứ nhất thì cách nói nhân vật "mắc nhầm lẫn" hàm ý dường như đang gián tiếp phê bình lỗi lầm của nhà văn (Le, 2009; Le, 2011). ${ }^{6}$ Giả dụ như thế thì nhà nghiên cứu sẽ trả lời sao đây câu hỏi đại loại "Vậy chờ đến năm Kiến An thứ 15 khi đài đã xây lên, phú được viết ra thì màn dẫn văn chương quân địch để khích tướng nước đồng minh của nhà thuyết khách cầm quạt lông này xử lí thế nào nữa?". Thành ra ta có thể nói chú thích của Hạ Chí Thanh vô tình đã biểu thị thái độ - tạm gọi là "nệ sử" của nhà nghiên cứu văn học. Gẫm kĩ đây không chỉ là một tâm lí "nệ sử" đơn thuần. Đây là trạng thái tâm lí không tách bạch trong ý thức việc thưởng thức tiểu thuyết với việc đọc sử. Vì nếu nhất quán với lập trường truy cứu sử thực kiểu đó, nhà nghiên cứu cũng nên chỉ thêm rằng La Quán Trung trước đó đã "sai lầm" (đương nhiên cũng là so với dữ liệu sử chí) về thời điểm khởi công xây đài. Sử Tam Quốc Chí quyển nhất chép chuyện Tào Tháo (Vũ Đế $K i$ 三國志·魏書·武帝紀第一) cho ta biết Đồng Tước Đài xây mùa Đông năm Kiến An thứ 15 (công lịch 210, tức sau sự kiện Xích Bích 2 năm; Kết hợp với quyển 19 kể chuyện Tào Thực, ta biết đài này hoàn thành cùng năm 210) (Tran, Bui, \& Tran, 1968). ${ }^{7}$ Như ta đọc thấy, tiểu thuyết đã không theo sử chí cố tình "đẩy” tình tiết khởi công xây đài sớm hơn mốc mùa Đông Kiến An năm thứ 15 ít nhất cũng phải hơn hai năm. Đương nhiên, điều quan trọng nên thấy là tiểu thuyết đã “đẩy thời gian” xây đài lên sớm hơn theo cách của nó. Thủ pháp tự sự về thời gian xây đài trong tiểu thuyết (không trực diện trần thuật thời điểm xây đài, chỉ đặt lẫn giữa những sự kiện khác) có lẽ đã giúp tác giả của nó tránh được áp lực phải công khai ra mặt chịu

\footnotetext{
${ }^{5}$ Nội dung chú thích "Nhị Kiều” xin xem quyển thượng 三國演義, 人民文學出版社, 2004, tr.366.

${ }^{6}$ Tại đây Hạ Chí Thanh chú thích: "Theo Tam Quốc Chí Thông Tục Diễn Nghĩa - quyển 10, tr.28a, Tào Tháo thiết tiệc nhằm ngày 15 tháng 11 năm Kiến An thư 13 (công nguyên, năm 208). Bởi vì trận Xích Bích diễn ra trong mùa đông năm này, cho nên thời gian trên là hợp logic. Mao Tôn Cuơng không tính cu thể đã lùi thời gian buổi tiệc sớm hơn một năm. Nhầm lẫn này đã được Trung Quốc Tác gia Xuất bản xã hiệu đỉnh trong bản in không phân tập Tam Quốc Diễn Nghĩa năm 1955. Bản in phân hai quyển năm 1953 thì vẫn để nhu cư". Không thể không ghi nhận công lao khảo cứu và thái độ học thuật nghiêm túc của nhà nghiên cứu. Nhân tiện xin nói thêm: trong trường hợp cần thiết ta cần phân biệt Tam Quốc Chí Thông Tục Diễn Nghĩa (bản của La Quán Trung tức Gia Tịnh Nhâm Ngọ bản, gọi tắt La bản) và Tam Quốc Chí Diễn Nghĩa (cha con Mao Tôn Cương tu nhuận trên cơ sở La bản, gọi tắt là Mao bản. Nhân dân Văn học Xuất bản xã tiếp tục dùng Mao bản nhưng không hiểu sao đã "rút gọn" nhan đề thành "Tam Quốc Diễn Nghĩa"). Xem thêm: Lê Thời Tân, "La Quán Trung, Mao Tôn Cương và diễn biến của sách Tam Quốc" (in trong Nghiên cúu và giảng dạy ngôn ngũu, văn hóa Việt Nam-Trung Quốc ở Đông Á và Đông Nam Á, Nxb.ĐHQGHN, 2009) hoặc "Lược sử sáng tác về đề tài Tam Quốc hay là một hình dung tự sự liên loại thể", Tap chí Khoa hoc ĐHQGHN, Ngoại ngü, số 27-2011

${ }^{7}$ Sử Tam Quốc Chí (Ngụy Thu thập cửu-Nhiệm Thành Trần Tiêu Vuoong truyện魏書十九任城陳蕭王傳第十九) đã chọn chép chuyện sáng tác Đồng Tước Đài Phú để mở đầu cho phần truyện Tào Thực (Trần Tiêu Vuoong Tào Thực Truyện): "Trần Tiêu Vương Tào Thực tự Tử Kiến, hơn mười tuổi đọc thông Kinh Thi, Luận Ngũ cho chí từ phú dài cả mấy vạn chữ. Thực giỏi văn chương, Thái Tổ (Tào Tháo) mấy lần đọc văn Thực hỏi "Nhà người nhờ người làm hộ phỏng?". Thực quỳ đáp: "Nói ra lời ấy là luận, hạ bút là thành văn. Xin phụ thân kiểm tra tại chỗ khắc biết, con việc gì phải nhờ người làm thay". Khi đó Đồng Tước Đài vừa xây xong, Thái Tổ bảo các con lên đài làm phú. Tào Thực cầm bút viết liền, ý tứ rất khả quan, Tào Công lấy làm kinh ngạc. (.....) Thực mỗi khi phụ thân chất vấn, hỏi đâu đáp đó rất được cha yêu. Kiến An năm thứ 16 (211) được phong Bình Nguyên Hầu"
} 
trách nhiệm đối chiếu "sử thuật". Và trong khi vòng tránh như thế, tác giả tiểu thuyết dường như đồng thời đã kín đáo bổ chính cho sử chí (ngôi đài quy mô như thế không thể từ thiết kế đến khánh thành chỉ trong một mùa Đông).

Nhưng cao hơn tất cả chuyện đó, La Quán Trung có lẽ là đang nhắm tới việc tái cấu trúc đề tài "Đồng Tước Đài” sao cho có thể khiến nó trở thành một không gian chứa đựng nhiều chuyện vốn đan xen tiếp nối ẩn hiện sinh động - những chuyện hoặc sẽ lọt sàng sự kiện của sử gia hoặc rồi sẽ bị sử gia rải dọc ra trên trục biên niên (編年紀) hay quy gom vào các ô (liệt) truyện/(bản) kỉ (紀/列傳) của từng nhân vật hoặc tập hợp lại theo triều đại quốc gia (thư). Đối chiếu với sử Tam Quốc Chí, mọi người đều thấy Đồng Tước Đài thực không dính dáng chuyện đánh Đông Ngô hay chuyện Nhị Kiều. Mà nếu vậy thì nói chuyện Tào Tháo xây sẵn đài cao để chờ lúc chinh phục xong Đông Ngô “khóa xuân hai Kiều” khác gì là đang cãi lại sử!

Lần mạch tự sự trong tiểu thuyết, ta thấy việc khởi dựng Đồng Tước Đài lần đầu tiên được kể ở đầu hồi 34. Lúc đó Tào Tháo chỉ mới dẹp xong Viên Thiệu và bình định thêm Liêu Đông nhưng chưa đủ sức Nam chinh nên đã giao việc xây đài cho hai anh em Tào Thực và Tào Phi (giao cho kiến trúc sư Thực là đủ, hà tất cứ phải để cả ông anh đang lo em tranh mất ngôi ở lại chung công đụng việc - tiểu thuyết gia dường như đang tính tới tương lai tự sự huynh đệ tương tàn sau này!) còn mình dẫn đại quân quay về Hứa Đô. Mãi về sau Tào Tháo mới khởi binh đánh Giang Nam. Tự sự tiểu thuyết mặc nhiên cho thấy cho đến lúc mở tiệc trên chiến thuyền giữa giòng Trường Giang thì Đài Đồng Tước nên là chuyện đã xong! Vậy tại sao Hạ Chí Thanh lại bỏ qua "sai lạc thời gian" này? Xem ra hoặc là ông không khảo cứu đầy đủ và hệ thống hoặc trừ lúc ý thức khảo cứu và tinh thần nệ sử chen ngang còn thì bình thường ông vẫn thưởng thức tự sự tiểu thuyết như vốn thế! Đọc kĩ Tam Quốc Chí Diễn Nghĩa đoạn này cần phải thấy rằng thực tế triển khai tình tiết sự kiện tự sự của tiểu thuyết là khá kín kẽ. Chỉ có nhà nghiên cứu ám ảnh khảo cứu một lúc chân đứng hai thuyền văn sử nên mới sơ hở mà không tự biết!

Mục đích chính của việc "đẩy lùi” thời gian xây đài Đồng Tước trong tự sự tiểu thuyết theo chúng tôi trước hết là nhằm kiến tạo chuyện Khổng Minh đọc phú Đồng Tước Đài bịa chuyện Tháo muốn đoạt hai Kiều để khích Chu Du. Cho dù La Quán Trung tự nhận chỉ là "diê̂̃n nghĩa" lịch sử và hậu nhân phổ biến cho rằng bộ diễn nghĩa này "bảy thực ba hư" đi nữa thì công việc của một nhà nghiên cứu văn học không nên quẩn quanh ở những khảo cứu đối chiếu văn sử cục bộ như thế. Quan trọng hơn cần tiến lên nhận thức được cái logic trần thuật nội tại của mỗi loại tự sự. Nói giản dị, “đài chim sẻ đồng” bên bờ sông Chương đó đã lưu danh "Đồng Tước" của nó vào trong Tam Quốc Chí và Tam Quốc Chí Diễn Nghĩa theo những cách khác nhau. Tiểu thuyết và sử kí đã khác nhau thì diê̂n nghĩa của nhà phê bình văn chương và nhà nghiên cứu lịch sử cũng đâu có thể cùng một cách thức!

Nói cho cùng, chả ai cấm được ta (phán đoán một cách nghiêm túc về mặt lịch sử hay chỉ là suy diễn tùy tiện về mặt văn chương) giả thiết rằng hai cha con nhà họ Tào có khi đã chia sẻ với nhau niềm cảm hứng Nhị Kiều ở một công trình kiến trúc và một tác phẩm thi ca ! Hoặc giả, cậu ba Thực lúc nêu ý thiết kế đài (chính tòa với cầu vồng nối hai tòa tả hữu) vô tình đã khiến cho phụ thân trong giấc mộng thôn tính nước người rõ thêm ý chiếm đoạt vợ người? Cũng không loại trừ khả năng lúc đó Tháo nghĩ đời mình thêm nữa cũng chỉ là bình định Giang Nam 
để cơ bản hoàn thành cơ nghiệp lớn là sẽ về "vui tuổi già" còn chuyện thoán Hán cướp ngôi thiên tử đợi đến thế hệ anh em Tào Phi, Tào Thực (dù gì đi nữa thì trong liên tưởng của một người đọc tinh tế các hình tượng đồng tước tam tòa, phụ tử tam nhân, tam phân nhất thống quả là đang ánh chiếu vào nhau để luyến láy chủ đề tam quốc). Đang lúc như thế vừa khéo lại có điềm lành "chim sẻ đồng" (liên hệ đến chuyện mẹ vua Thuấn mộng thấy sẻ ngọc bay vào lòng mà sinh Thuấn) nên khởi ý xây Đồng Tước Đài. Trước làm chốn dưỡng già sau biết đâu lại thành thánh tích khai triều lập quốc ! Phỏng đoán như thế cũng là một cách cắt nghĩa tại sao Tháo không những đồng ý ngay bản thiết kê ngôi đài của Tào Thực đồng thời lại còn giao việc trông coi xây đài cho Tào Thực và Tào Phi! Chuyện ra sao đi nữa thì sau cùng cầu kiều đã bắc mà nguời kiều chả qua. Con chim sẻ bằng đồng im vùi dưới đất bao năm rốt cuộc cũng chỉ là lấp lánh một thoáng kim quang trong giấc mơ vượt sông Trường Giang của Tào Thừa tướng mà thôi ! Sự thực cá biệt của lịch sử làm sao có thể phản ánh hết được những dáng vẻ mờ tỏ giữa đời. Cũng như chuyện tâm lí câu nệ khảo cứu chắc chắn sẽ ảnh hưởng ít nhiều đến tầm cao rộng của sải cánh tự do tiếp nhận nghệ thuật.

Tiểu thuyết Tam Quốc Chí Diễn Nghĩa (hồi 56) cũng giữ đúng thời gian hoàn công Đồng Tước Đài năm 210 như trong sử chí. Chỉ có điều điều trần thuật màn hoàn công đài của tiểu thuyết kể chuyện Tháo hội đủ văn võ bá quan thi bắn tên làm thơ ăn mừng Đồng Tước Đài mà không có tình tiết Tào Thực lên đài viết phú. Trong lúc đó, sử Tam Quốc Chí nói rõ Thực làm bài phú trong dịp khánh thành Đồng Tước Đài. Trong tiểu thuyết, chi tiết Tào Thực làm bài phú đã được gián tiếp thông tin từ hồi 44 qua tình tiết Khổng Minh dẫn bài phú làm chứng với $\mathrm{Chu} \mathrm{Du}$ việc cha con họ Tào quả nuôi ý cướp nước chiếm vợ. Rõ ràng tác giả tiểu thuyết đã cố tình mơ hồ hóa và tránh trực diện với chi tiết thời điểm Tào Thực sáng tác bài phú. Nhờ đó, tiểu thuyết đã khiến cho bạn đọc nhất là những bạn "biết sử" sau khi đọc xong cả sử lẫn văn tự hiểu lấy rằng chuyện đời rất có thể là Tào Thực đã hoàn thành việc sáng tác bài phú từ lâu, hôm đăng đài khánh thành chẳng qua chỉ là bút giấy trước quan khách như là một màn biểu diễn (liveshow) mà thôi. Nếu cảm hiểu như thế thì dường như cũng có thể phỏng đoán rằng rất có thể Tào Tháo cho đến khi đó vẫn đang nuôi ý để Tào Thực kế vị. Đối chiếu kĩ hơn sử và văn ta còn thấy trần thuật của Tam Quốc Chí đặt tình tiết Thực tức cảnh viết phú như là một cách ứng khảo tỏ thực tài, chứng minh việc phụ vương nghi ngờ (chả biết Tháo nghi thật hay làm bộ giễu con như thế trước quần thần) chuyện có thể ai đó thường gà hộ văn thơ cho Thực là sai. Đây là một motip thường thấy của sử khi làm liệt truyện cho một nhân vật. Độ sáo mòn của tình tiết này trong sử khiến cho ý vị tự sự của nó giảm hẳn đi. Trong lúc đó tiểu thuyết đã chuyển hóa tình tiết này vào trong một màn trần thuật đầy sức căng kịch tính và thấm đẫm hơn rất nhiều ý vị đời sống - màn “thất bộ thi” (七步詩đầu hồi 79): Thực buộc phải tỏ tài trước mặt anh cả để cứu lấy mạng sống của bản thân chứ không phải là tỏ tài để được bố yêu (phụ vương đã chết). Tự sự của tiểu thuyết từ trước đó thực ra đã từng bước ám thị độc giả thấy được rằng chính niềm yêu riêng của bố mới là nguyên do đẩy đến kết cục "củi đậu nấu hạt đậu". Mà cảm tình của Tháo dành cho đứa con thứ ba kể cũng là chuyện rất tự nhiên - người cha nhìn thấy nơi người con bóng hình của chính hắn - tài thi phú cùng phong độ nhà nghệ sĩ, thậm chí cả khuyết điểm bất lợi cho công việc là tính ham rượu! Chuyện ham rượu làm lỡ đại sự và thói phóng túng không giữ lễ thì chính phụ vương đã tỉnh táo nhận ra khi trối trăng với đám cận thần không giao cơ nghiệp cho thằng em nhưng mà niềm ghen tài và tâm lí đố kị em được bố yêu của ông anh thì phải chờ đến lúc bố mất mới bộc phát hoàn toàn. Đó chính là lí do tại sao mà khác với 
Tam Quốc Chí tác giả tiểu thuyết lần lượt thêm các màn trần thuật Tào Tháo trối trăng chuyện con cái nối nghiệp và màn anh cả Tào Phi toan chẹt em Tào Thực vào chỗ chết ngay khi phụ vương vừa nhắm mắt xuôi tay (hồi 79) (La, Mao, \& Mao, 2009). ${ }^{8}$ Đương nhiên chuyện nồi da xáo thịt nội tộc họ Tào lúc đó còn do xúi dục của người ngoài - kẻ chạy từ bên Ngô sang nữa. Kẻ đó là Hoa Hâm. Đến đây độc giả tinh tường sẽ hiểu được tại sao xa tận hồi 55, 56 tác giả tiểu thuyết đã chu toàn chêm cài tình tiết Hoa Hâm đi sứ Hứa Đô nửa đường rẽ sang Nghiệp Quận bái kiến Tào Tháo đang dự lễ khánh thành Đồng Tước Đài! Những tính toán trần thuật như thế làm cho tự sự tiểu thuyết trở nên tinh tế và thâm trầm hơn biết bao so với kí tải của sử chí. "Đồng Tước Đài" vì thế đã trở thành một từ khóa xuyên kết cả một loạt câu chuyện lớn liên quan đến không chỉ ba kẻ không cùng một nước (Du-Lượng-Tháo) trước bước ngoặc Xích Bích thiên hạ thực sự tam phân mà cũng là một từ khóa quan trọng trong câu chuyện ba cha con một nhà (xoay quanh vấn đề kế vị) khởi đầu bước ngoặc mới - thiên hạ không còn thiên tử chung, tam quốc lần lượt xưng đế. Lấy cái nhãn quan tự sự tiểu thuyết đó ra mà nhìn lại lịch sử thời đại hóa ra mọi chuyện không chỉ quyết ở một cơn trở gió Đông trên trời cao Giang Nam mà xa hơn đã khởi tự chớp lòe của con sẻ đồng dưới đất sâu Hà Bắc (Tào Tháo đang đêm lên thành quan sát thấy xa xa ánh sáng lóe lên từ dưới đất, cho người đến đào được chim sẻ đồng)! Thế nên có thể khẳng định rằng rất có khả năng tác giả Tam Quốc Chí Diễn Nghĩa đã được gợi hứng từ bài tứ tuyệt bất hủ của Đỗ Mục khi xây dựng câu chuyện Đồng Tước Đài. Thi phẩm này chắc đã khiến La Quán Trung quyết định đương đầu với sử gia cho "xây" ngôi đài sớm hơn mốc thời gian chép trong sử. Nhà tiểu thuyết thậm chí không sợ làm "lộ" kết cục và mất hứng thú theo dõi câu chuyện khi quyết định dẫn bài thơ vào lúc Đại chiến Xích Bích chỉ mới kể tới chỗ chớm hé cao trào. ${ }^{9}$ Cao kiến và mẫn cảm của nhà tiểu thuyết chủ yếu bộc lộ ra ở chỗ biết tóm lấy một tiếng "KIỀ" để liên kết một loạt các chi tiết xoay quanh Đài Đồng Tước - những chi tiết vốn rất rời rạc và cô lập trong tự sự sử học (Tam Quốc Chî). Nhà nghiên cứu cần chú ý nhiều hơn đến sự khác biệt giữa tự sự tiểu thuyết và tự sự sử truyện. Tự sự diễn nghĩa như một tấm thảm thêu dệt tinh vi. Bức thảm đó kết hợp nhiều mũi kim nhiều sắc chỉ. Đó là điều mà tự sự sử truyện tiêu biểu là Tam Quốc Chí với cách chia ba Ngụy Chí/Thục Chí/Ngô Chí rồi trong mỗi phần đó tự sự câu chuyện chung của thời đại bằng một dãy liệt truyện các nhân vật (kể riêng từng nhân vật hoặc gộp kể vài ba kẻ thành một hợp truyện) không thể làm được. Tự sự Tam Quốc Chí không thể là tấm thảm dệt đa sắc nhiều lớp, cùng lắm chỉ so sánh được với một tập tranh chân dung mà cảnh nền của mỗi bức bắt buộc trùng lắp rất nhiều họa tiết. Tự sự tam phân (Ngụy-Thục-Ngô) xếp dãy nhân vật (kỉ/truyện) kiểu Tam Quốc Chi tưởng rõ ràng ngắn gọn "đầy đủ” nhưng rốt cuộc lại trùng lắp và khó hiểu (nhìn lượng khối lượng chú dẫn đồ sộ của Bùi Tùng Chi cho Tam Quốc Chí là đủ thấy vấn đề ${ }^{10}$ ). Tuy nhiên câu chuyện ở đây không ở chỗ so sánh văn sử cao thấp mà quan trọng hơn là phương thức, phong cách cùng một logic

\footnotetext{
${ }^{8}$ Hồi 79 kể chuyện "thất bộ thi” Tào Phi hạch tội Tào Thực. Tam Quốc Chí (kể cả chú giải của Bùi Tùng Chi) hoàn toàn không có chuyện này. Tiểu thuyết rất có thể đã sử dụng tích chuyện này từ Thế Thuyết Tân Ngũ (世說 新語do Nam Triều Lưu Nghĩa Khánh chủ trì biên soạn)

${ }^{9}$ 赤壁 (杜牧): 折戟沈沙鐵未銷, 自將磨洗認前朝。東風不與周郎便, 銅雀春深銷二喬。Đông phong bất dữ Chu Lang tiện, Đồng Tước Xuân thâm tỏa nhị Kiều (Chàng Chu mà chẳng gió Đông giúp, Chim Sẻ đài kia đã nhốt Kiều)

${ }^{10}$ Bùi Tùng Chi (裴松之372 - 451) hoàn thành công trình bình chú Tam Quốc Chí vào khoảng 729 theo lệnh của vua Văn Đế (Tống). Phần chú giải bổ sung dày gấp bội so với cuốn sử của Trần Thọ. Những tài liệu mà Bùi dùng cho chú dẫn phần lớn đã thất truyền
} 
trần thuật nội tại của mỗi loại tự sự. Nhà nghiên cứu văn học tránh không nên dẫm chân mãi ở bãi lầy khảo cứu đối chiếu hai cái gọi là sử liệu văn liệu. Hạ Chí Thanh trong trường hợp chúng tôi dẫn trên đã tỏ ra quá ư nệ sử. Mải vận dụng kiến thức sử kí để chú dẫn một cách cô lẻ tình tiết tự sự trong tiểu thuyết khiến ông quên đi bản thân mình thực ra đang "vãng cảnh" ngôi đài được "dựng lên" trong văn chương chứ không chỉ là một di tích bên bờ con sông lịch sử !

Học giả đời Thanh Chương Học Thành chê trách Tam Quốc Diễn Nghĩa "hu cấu pha tạp, ngôn tù̀ trùng lắp dễ sinh ra lẫn lộn" "bảy thực ba hu làm rối loạn nguời đọc" "“tạp hư từ phục, dị tư hỗn hào" "thất thực tam hư hoặc loạn quan giả") (Lo, 1997, p. 150). ${ }^{11}$ Đôi khi ta cũng phải băn khoăn cớ gì mà kẻ đội mũ sử gia lại đi níu áo người khoác áo tiểu thuyết gia ? Nỗi lo của học giả họ Chương kể ra cũng hơi vô lối - làm sao mà quản được tiếp nhận tự do của độc giả và quy được trách nhiệm sử gia cho nhà tiểu thuyết! Thực tế không có lí gì để có thể đánh giá tiểu thuyết này theo một lập trường sử học thuần tuý như vậy. Vả chăng bảy thực $b a$ $h u$ cũng chỉ là một cách nói. Cần biết La Quán Trung diễn nghĩa lịch sử bằng một trọn vẹn tiểu thuyết (演義, The yanyi of History of the Three Kingdoms). ${ }^{12}$ Ta không thể đánh giá bộ tiểu thuyết bằng lối khảo đối tỷ lệ thực hư thuần túy sử học như vậy. Và ta cũng không thể xem cái gọi là hư cấu diễn nghĩa chỉ như là một phần gia tăng thêm vào trong tác phẩm bên cạnh những tài liệu chứng minh rõ được là lấy từ nguồn sử liệu nào đó như ý của Lỗ Tấn (người đã dẫn Chương Học Thành khi bàn về Tam Quốc Chí Diễn Nghĩa). Xem ra nỗi niềm gian díu vướng vất giữa sử và văn biểu hiện ra trong tiếp nhận và nghiên cứu văn học vẫn là câu chuyện trường thiên. Chương Học Thành để đời bộ Văn Sủ Thông Nghĩa (文史通義). Chúng tôi mạo muội cho rằng một nhà nghiên cứu thông được yếu nghĩa của Văn lẫn Sử phải là người tiến đến chỗ thấy rằng văn hay sử cũng là tự-sự (naration/narrative) cả mà thôi. Mà một khi đã hiểu được sử và văn ấy đều là tự sự thì hà tất phải quá lo chuyện thưc hu rối loạn lòng người nữa! Ngày nay thay vì dùng cách nói truớc tác lịch sủ và viết tiểu thuyết, nhiều nhà nghiên cứu phê bình văn học phổ biến cách nói tư sư lịch sủ và tư sư văn học. Chúng tôi lạm nghĩ, cách nói đó chắc không đến nỗi làm cho những người xưa nay chắc mẩm sử đã chép là (có) thực lấy làm khó chịu (Le, 2013). ${ }^{13}$ Thưởng thức trở lại tình tiết tự sự "Nhị Kiều - Đồng Tước Đài” gắn liền với những chú khảo của nhà nghiên cứu Hạ Chí Thanh cũng là dịp để ta nhận thức lại hoặc nói đúng hơn - thức nhận theo một lối mới cái gọi là "văn sử bất phân" của người Trung Quốc ${ }^{14}$.

\footnotetext{
11 “雜虛辭复易滋混淆七實三虛”, “惑亂觀者” (丙辰雜記). Dẫn lại từ Lỗ Tấn, Trung Quốc Tiểu Thuyết Sủ Luợc (中国小说史略). Sự phổ biến của sách này đã làm cho bình luận đó được phổ biến rộng hơn. Giới nghiên cứu dẫn lại Chương Học Thành thường chỉ chú ý đến mấy chữ "bảy thực ba hư" vô tình hay cố ý không nhắc đến phần "làm rối loạn người đọc" tỏ rõ ý phê bình Tam Quốc Diễn Nghĩa của họ Chương

${ }^{12}$ Sử chí, thuyết thư, giảng sử tạo nền tảng cho Tam Quốc Chí Diễn Nghĩa. Có thể xem bộ sách này như là món cocktail của tự sự Trung Quốc. Cất công xác định tỷ lệ "thực hư", công thức pha trộn các nguồn tài liệu là cần thiết. Nhưng thưởng thức nó sau khi đã pha xong còn quan trọng hơn. Lịch sử là quá khứ - một quá khứ chờ tương lai "bạch hóa" hồ sơ lưu trữ. Trong khi chờ đợi độc giả không ngại đọc các "diễn nghĩa" hoặc nghe vài " thuyết thư " vậy

${ }^{13}$ Câu đầu cửa miệng của họ là "Trong sủ có chép/nói...". Thiển nghĩ bia đá có khi mòn mà chắc gì bia miệng còn được trơ trơ!

${ }^{14}$ Xem thêm Lê Thời Tân, “Tam Quốc: lịch sử diễn nghĩa và diễn nghĩa lịch sử”, Tạp chí Nghiên cứu Trung Quốc, số $2 / 2013$
} 


\section{Tài liệu tham khảo}

Hsia, C. T. (2001). Trung Quốc Tiểu thuyết Sủ luận [Chinese history novel] (D. I. Ho, L. H. Thach, \& C. K. Don, Trans.). Jiangxi, China: Giang Tây Nhân dân xuất bản xã.

La, T. Q., Mao, L., \& Mao, C. T. (2009). Tam quốc diễn nghĩa [China's three kingdoms]. China: Trung Hoa Thư Cục xuất bản.

Le, T. T. (2009). La Quán Trung, Mao Tôn Cuong và diễn biến của sách Tam quốc in trong nghiên cúu và giảng dạy ngôn ngũu, văn hóa Việt Nam-Trung Quốc ở Đông Á và Đông Nam Á [La Quan Trung, Mao Ton Cuong and developments of the Three Kingdoms book printed in research and teaching on Vietnamese-Chinese language and culture in East Asia and Southeast Asia]. Hanoi, Vietnam: NXB Đại học Quốc gia Hà Nội.

Le, T. T. (2011). Lược sử sáng tác về đề tài Tam quốc hay là một hình dung tự sự liên loại thể [A history of composing on the topic of the Three Kingdoms or an inter-genre narrative visualization]. Tạp chí Khoa học Đại học Quốc gia Hà Nội, Ngoại ngũu, 27.

Le, T. T. (2013). Tam Quốc: Lịch sử diễn nghĩa và diễn nghĩa lịch sử [Three Kingdoms: Historical interpretations and historical meanings]. Tạp chí Nghiên cúu Trung Quốc, 2.

Le, T. T. (2013). Tự sự học lịch sử và tự sự học văn chương - Suy nghĩ nhân một tình tiết bình chú Tam quốc diễn nghĩa của Nhân dân Văn học Xuất bản Xã [Historical narrative and literary narrative - Thoughts on an episode commentary on the Three Kingdoms 'meaning of the People' s Literature Publishing]. Tạp chí Nghiên cúu Văn học, 3.

Lo, T. (1997). Trung Quốc tiểu thuyết sủ lược [Chinese novel history]. China: Tề Lỗ Thư Xã xuất bản.

Tao Thuc (1998). Tào tư kiến tập bình chú. Taiwan: Đài Loan Thế giới Thư Cục xuất bản.

Tran, T., Bui, C. T., \& Tran, C. N. (1968). Tam quốc chi [Records of the three kingdoms]. Taiwan: Đài Loan Trung Hoa Thư Cục xuất bản. 